medical students, with many students asking 'Why is this session not used in more departments in the hospital/on more occasions throughout medical school?'. Other comments included: 'Such a fantastic example of how a department should be and the kind of positive environment every department should strive for'.

Conclusion Two similar sessions were repeated within Paediatrics, and a session was also introduced to the Haematology department. Additional positive feedback emphasised the value of this work.

Instilling positivity from an early stage has the potential to shape the future careers of medical students, and spark enthusiasm for pursuing a career in Paediatrics. We believe that this is an initiative which can benefit everyone - 'Positivity is like a boomerang - the more we put it out there, the more it comes back to us', and we look forward to expanding the project further.

\section{G201(P) UNDERSTANDING THE EXPERIENCE OF TRANSITION FROM SENIOR HOUSE OFFICER TO REGISTRAR FOR PAEDIATRIC SPECIALITY TRAINEES IN WALES, DISCOVERING THE LEARNING NEEDS AND WHAT IS PERCEIVED TO EASE THE EXPERIENCE} 1,2SMA Alam, 1,2 L Allery. 'Medical Education, Cardiff University, Cardiff, UK; ${ }^{2}$ Birmingham
Children's Hospital, West Midlands Deanery, Birmingham, UK

\subsection{6/archdischild-2020-rcpch. 170}

Aims The transition from senior house officer to the registrar grade has limited study in existing literature, providing narrow insight into the learning needs of paediatric trainees at this junction, or the educational practices that may optimise the experience of transition. This qualitative study examined the perceptions of such paediatric trainees in order to: 1) understand trainee perception about their positive and negative experiences of transition to the registrar grade; 2) identify their learning needs; 3) derive educational interventions to ease the experience of transition.

Methods University Ethics approval and informed consent was gained. Six Wales Deanery paediatric ST3 and ST4 trainees were questioned via semi-structured interview using critical incident technique. Transcribed responses were thematically analysed until data-sufficiency was achieved.

Results Fourteen learning needs were identified, dichotomised to clinical skills or leadership and management skills. Clinical skills included child protection assessment, difficult communication scenarios, emergencies, a dying child, difficult procedures, tertiary neonates, family anxiety and expectations, dealing with uncertainty and running clinics. Leadership and management skills included clinical decision making, leading ward rounds, managing workload, leading a team and supervising juniors. Six educational interventions were derived: acting-up, feedback, senior support, staff support, familiarising with the initial ST4 placement and maximising SHO learning opportunities.

Conclusion The following recommendations for practice change to improve the experience of transition for paediatric trainees target five key stakeholders. Trainees could focus PDPs toward identified learning needs and volunteer for acting-up opportunities. Seniors should routinely offer trainees to lead ward rounds and clinics, provide feedback constructively avoiding criticism, and directly touch base with transitioning trainees prior to and during out-of-hour shifts, stressing their availability to address concerns. Support is also important from senior registrars offering mentorship, or from nursing staff offering leeway and avoiding potentially undermining behaviour. Educators should target step-up courses and study/ simulation days to address aforementioned learning needs, in particular leadership and management skills. Educators should ensure the first ST4 placement is at a centre familiar to the trainee, whilst rota coordinators should introduce out-of-hour shifts in a stepwise manner from evenings to nights, whilst ensuring an appropriate skill mix of supporting staff.

\section{G202(P) EDUCATIONAL EXPERIENCE OF PAEDIATRIC SPECIALTY TRAINEES IN OUTPATIENT CLINIC SETTINGS: IS THERE ROOM FOR IMPROVEMENT?}

${ }^{1,2} \mathrm{M}$ Neocleous, ${ }^{2,3} \mathrm{MG}$ D'Costa, ${ }^{2,4} \mathrm{G}$ Cleary. ${ }^{1}$ Neurology Department, Alder Hey Hospital, Liverpool, UK; ${ }^{2}$ University of Liverpool, University of Liverpool, Liverpool, UK; ${ }^{3}$ Medical Education, Alder Hey Hospital, Liverpool, UK; ${ }^{4}$ Rheumatology Department, Alder Hey Hospital, Liverpool, UK

\subsection{6/archdischild-2020-rcpch. 17}

Background Clinic experience is vital to paediatric specialty training, especially given current trends towards managing patients on an outpatient basis. Challenges contributing to substandard educational experiences in paediatric training include difficulties in recruitment and retention as well as poor access to outpatient clinics. Whilst RCPCH campaigns such as Paediatrics 2040 and \#choosepaediatrics may resolves some of these issues, standardised provision for outpatient clinic training may also help.

Aims This baseline audit evaluated paediatric trainees' clinic experience whilst on placement at a tertiary paediatric centre, focusing on quantifying the average number of clinics attended and exploring opportunities or barriers to achieving training within this context.

Methods A link to an online questionnaire was sent to paediatric trainees via e-mail and WhatsApp groups. Printed forms were also distributed during handovers to encourage greater response rates. Qualitative and Quantitative data were collated and subsequently analysed.

Results The return rate was $61 \%$ with 31 out of 51 trainees from eight different specialties responding. 52\% of trainees reported that clinic attendance was timetabled within their work schedule and that they usually attended one to two clinics per month. However, 23\% had not attended any clinics within the last month and a significant number of trainees reported barriers, which included feeling uncomfortable handing over ward commitments (52\%) or being pulled from clinic to cover other duties including holding the on-call bleep $(10 \%)$ or routine ward work (13\%). Trainees generally found clinics educationally valuable with $36 \%$ receiving constructive feedback. The majority of trainees supported initiatives to improve clinic attendance including scheduled clinics (77\%) and a clinic booking system (32\%).

Conclusions The results from this survey illustrate a need for enhanced provision of clinic exposure within specialty paediatric training. A series of improvements are planned in the next phase of this quality improvement project including the introduction of scheduled clinics, publication of a clinic timetable and the pilot of an innovative mobile app booking system which has been designed in conjunction with the trust innovation team. 